\title{
Introduction of a New Conventional SEM: JSM-IT300LV: The Observation of a Water Containing Specimen With a Cooling Stage at 650 Pa
}

\author{
N.Inoue ${ }^{1}$, T.Kaneko $^{1}$, D.Edwards ${ }^{2}$, D.Guarrera ${ }^{2}$, K.Kawauchi ${ }^{1}$ \\ 1. JEOL Ltd., 1-2 Musashino 3-chome, Akishima, Tokyo, 196-8558, JAPAN \\ 2. JEOL USA Inc. 11 Dearborn RD, Peabody, MA, 01960, USA
}

The scanning electron microscope (SEM) is a versatile instrument for the investigation of a wide variety of materials. The advent of the low vacuum technology for SEM has simplified specimen preparation and widened the range of materials that can be investigated with this technique. Charging artifacts can be controlled or eliminated and non-vacuum compatible samples (out-gassing, hydrated specimens etc.) can be imaged. Recently, we have developed a new SEM, JSM-IT300LV which can be operated in both high and low vacuum modes; where the low vacuum mode ranges from 10 to $650 \mathrm{~Pa}$. Figure 1 shows a schematic diagram of the JSM-IT300LV optics. A key feature of this SEM is a new differential evacuation system. The evacuation is carried out through three channels; one in the gun chamber, one near the objective lens aperture area and also one lower at the objective lens. The system results in an image with a higher signal to noise ratio, especially in the low vacuum mode. This report describes an application to water containing specimens of this new JSM-IT300LV in the low vacuum mode (at 650 $\mathrm{Pa}$ ) with a cooling stage. It is common to freeze water containing specimens for observation in an SEM. However, this freezing can produce artifacts due to the expansion of ice. Figure 2 shows the phase diagram of water. To maintain water in the specimen and avoid artifacts caused by freezing, it is necessary to cool the specimen to $1^{\circ} \mathrm{C}$ and maintain a pressure at $650 \mathrm{~Pa}$. For this study, we used konjak (konnyaku) as a model specimen. Konjak as a form of jelly is made from konjak flour and consists of approximately 95 mass\% water. The specimen will easily dehydrate and deform under normal evacuated pressure conditions. Figure 3 shows a photo of konjak set on the Coolstage. Black grains within konjak are seaweed. Figures 4(a) and (b) show the backscattered electron (BSE) images in the low vacuum mode without coating. Figure 4(a) shows a hitherto observed image at ambient temperature in a low vacuum at $30 \mathrm{~Pa}$. The specimen shows artifacts due to dehydration; where the collapse of seaweed cells is evident. Figure 4 (b) shows an image at $1^{\circ} \mathrm{C}$ and $650 \mathrm{~Pa}$ using the Coolstage. We can clearly observe a konjak image showing fibers and seaweed cells. Other applications to water containing specimens will also be presented.

Instruments: The JSM-IT300LV SEM can be used along with the Coolstage from DEBEN (UK). This Coolstage utilizes a Peltier system for temperature control from $-25^{\circ} \mathrm{C}$ to $+50^{\circ} \mathrm{C}$.

References:

[1] Kauzmann, Eisenberg “mizunokouzoutobussei”, misuzusyobou (1975) 


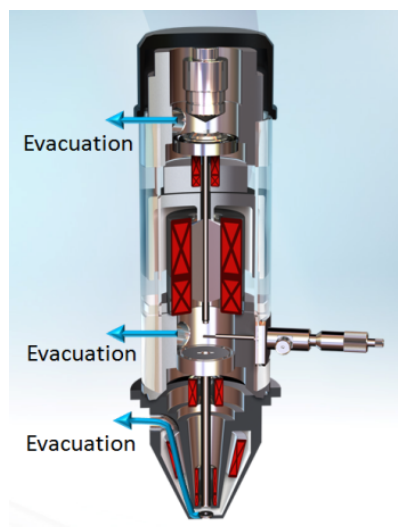

Fig. 1 The vacuum system in JSM-IT300LV

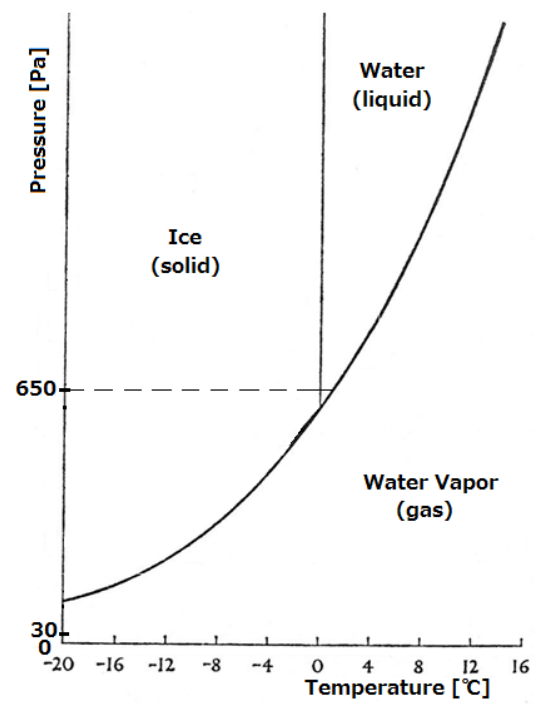

Fig. 2 The phase diagram of

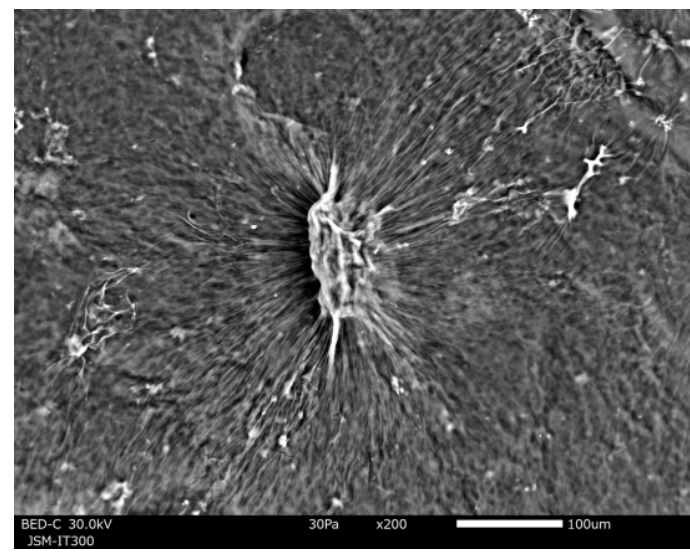

(a)

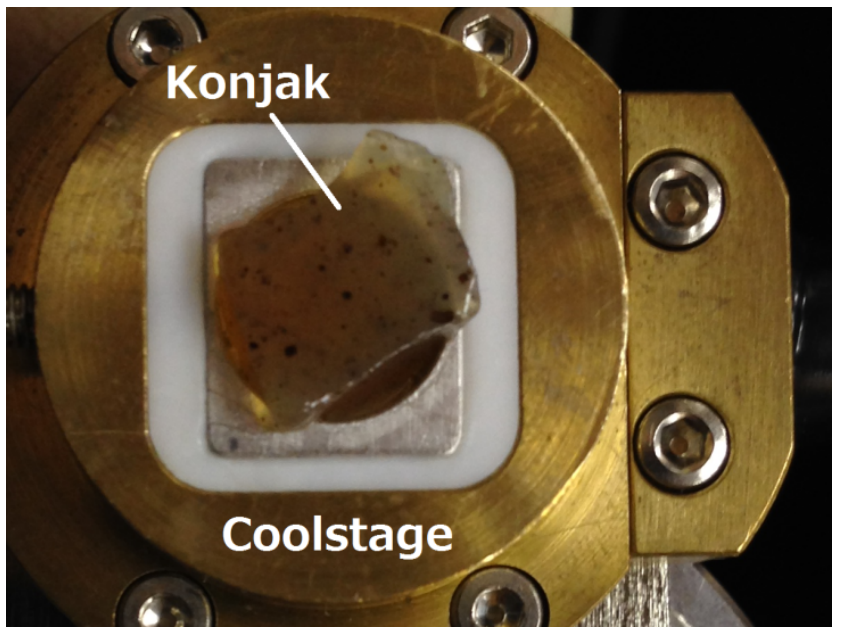

Fig. 3 Konjak set on the Coolstage.

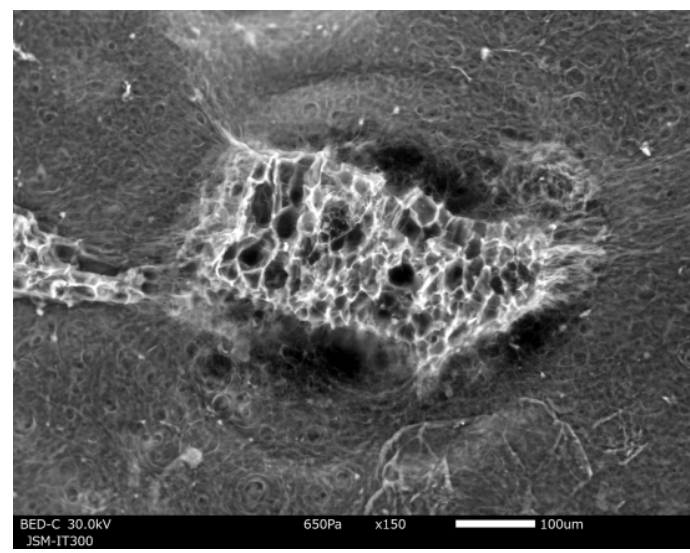

(b)

Fig. 4 BSE compositional images of a water-containing specimen.

(a) Room temperature, $30 \mathrm{~Pa}$

(b) $1^{\circ} \mathrm{C}, 650 \mathrm{~Pa}$ with the Coolstage 